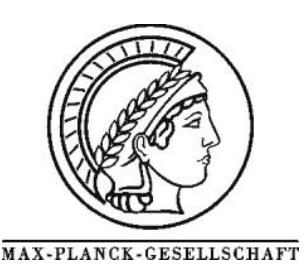

\title{
A comparative in situ XPS study of PtRuCo catalyst in methanol steam reforming and water gas shift reactions
}

\author{
S. Zafeiratos ${ }^{\mathrm{a}}$, F. Paloukis ${ }^{\mathrm{b}}$, G. Papakonstantinou ${ }^{\mathrm{b}}$, D. Teschner ${ }^{\mathrm{c}}$, M. Hävecker ${ }^{\mathrm{c}}$, E. Vass ${ }^{\mathrm{c}}$, P. Schnörch ${ }^{\mathrm{c}}$, \\ A. Knop-Gericke ${ }^{\text {c }}$, R. Schlögl ${ }^{\text {c }}$ B. Moreno ${ }^{\text {d }}$, E. Chinarro ${ }^{\text {d }}$, J.R. Jurado ${ }^{\text {d }}$, S.G. Neophytides ${ }^{\text {b }}$ \\ ${ }^{\text {a }}$ LMSPC, UMR 7515 du CNRS, 25 Rue Becquerel, 67087 Strasbourg, France \\ ${ }^{\mathrm{b}}$ ICEHT-FORTH, GR-26504 Rion, Achaias, Greece \\ ${ }^{c}$ Fritz-Haber-Institut der MPG, Faradayweg 4-6, D-14195 Berlin (Dahlem), Germany \\ d Instituto de Cerámica y Vidrio, CSIC. Cam. de Cantoblanco, C/Kelsen 5, 28049 Madrid, Spain
}

* Corresponding author: e-mail spirosz@ecpm.u-strasbg.fr,

Published Online: 18 April 2010

\begin{abstract}
In the present study the oxidation state and the surface composition of a ternary PtRuCo catalyst were investigated under methanol steam reforming (SRM) and water gas shift (WGS) reaction conditions at $570 \mathrm{~K}$. Ambient pressure X-ray photoelectron spectroscopy (APPES) was applied in situ at 0.5 mbar, while simultaneously monitoring the catalytic activity of the sample by on-line mass spectrometry. Non-destructive depth profile measurements performed under SRM reaction conditions over a polycrystalline PtCo foil, were also used to obtain detailed depth-resolved information. The results showed that surface segregation of cobalt and modification of its oxidation state occurs when switching from SRM to WGS reaction conditions. Evidence of ionic Pt was found only during WGS reaction, while Ru was mainly present in the metallic state. The results clearly demonstrate the dynamic response of the PtRuCo catalytic surface to the reaction atmosphere.
\end{abstract}

Keywords: Direct methanol fuel cells; Ambient pressure photoelectron spectroscopy; Methanol steam reforming reaction; Water gas shift reaction; PtRuCo catalyst

\section{Introduction}

Fuel cells using methanol as a fuel have a high potential for future energy applications. In these cells methanol is electro-oxidized at the anode in the presence of water generating $\mathrm{CO}_{2}$, hydrogen ions and electrons traveling through the external circuit as the electric output of the fuel cell [1] and [2]. The excellent catalytic activity of Pt makes this metal electro-catalyst ideal for use as an anode in direct methanol fuel cells (DMFCs). However, the Pt metal surface gets easily poisoned and deactivates at low temperatures by trace amounts of adsorbed $\mathrm{CO}$, which forms as a by-product of methanol electro-oxidation [1], [3] and Considerable effort has been made to design and synthesize Ptbased binary and ternary systems, which enhance the catalytic activity by eliminating or inhibiting the CO-poisoning effect [4] and [5]. The addition of Ru [6] and [7], Mo [8], Sn [4] and [9] and W [10] to platinum has been studied as candidates of sustainable CO tolerant bimetallic catalysts. The $\mathrm{Pt}-\mathrm{Ru}$ has shown superior performance compared to any other bimetallic catalyst and is now recognized as the most promising electro-catalyst for DMFCs [11]. However, the performance of carbon supported $\mathrm{Pt}-\mathrm{Ru}$ is still not sufficient and more active catalysts are needed for commercialization of DMFC technology. Recent theoretical and experimental studies of ternary and quaternary alloy catalysts of PtRuM ( $\mathrm{M}=\mathrm{Co}, \mathrm{Ni}, \mathrm{W})$ have shown that PtRuCo significantly promotes the methanol oxidation reaction and is more resistant against $\mathrm{CO}$ poisoning than the bimetallic PtRu system [12] and [13].

In the present work we studied methanol and carbon monoxide catalytic oxidation in the presence of water 
(SRM and WGS reactions respectively) over a PtRuCo catalyst. The main aim was to identify the nature of the working catalytic surface, hence providing the basis for understanding the beneficial effects of $\mathrm{Ru}$ and Co promoters on Pt. Both reactions were performed at $570 \mathrm{~K}$ and at 0.5 mbar total pressure, with simultaneous monitoring of the catalytic surface using synchrotron-based ambient pressure photoelectron spectroscopy (APPES) [14]. Additionally to PtRuCo, the SRM reaction was also studied over a polycrystalline PtCo foil in order to clarify issues related to the surface arrangement of the components. To the best of our knowledge this is the first time that an electro-catalyst, promising for DMFC applications, is characterized under working conditions of methanol and $\mathrm{CO}$ oxidation reactions, using surface sensitive methods.

\section{Experimental}

The unsupported PtRuCo catalyst (nominal composition $\left.\mathrm{Pt}_{0.375} \mathrm{Ru}_{0.375} \mathrm{Co}_{0.25}\right)$ used in this study was prepared by combustion synthesis [15]. The PtRuCo powder was ground in a mortar and sized using a $63 \mu \mathrm{m}$ mesh. The transmission electron microscopy (TEM) images showed that the catalyst forms soft agglomerates, composed of nanocrystalline highly dispersed PtRuCo particles in the range of $10-17 \mathrm{~nm}$. In the X-ray diffraction (XRD) pattern an angle shift of Pt peaks compared to pure Pt was observed, consistent with Pt-based alloy formation with $\mathrm{Ru}$ and/or Co in the bulk. For the polycrystalline $\mathrm{Pt}_{0.5} \mathrm{Co}_{0.5}$ (99.99\% purity) foil, bulk alloy formation was also indicated in the XRD results.

In situ X-ray photoelectron spectroscopy (XPS) experiments were performed at the beamlines U49/2-PGM1 and ISISS at BESSY II in Berlin, in a set-up described elsewhere [16] and [17]. About $70 \mathrm{mg}$ of PtRuCo powder were pressed forming a ca. $0.5 \mathrm{~mm}$ thick and $5 \mathrm{~mm}$ diameter pellet and placed on a sample holder, which could be heated from the rear by an IR laser (cw, $808 \mathrm{~nm}$ ). The temperature was measured by a K-type thermocouple fixed on the sample surface and the typical heating rate was $20 \mathrm{~K} / \mathrm{min}$. $\mathrm{CH}_{3} \mathrm{OH}, \mathrm{H}_{2} \mathrm{O}, \mathrm{CO}, \mathrm{O}_{2}$ and $\mathrm{H}_{2}$ gas flow into the reaction cell was controlled using mass flow controllers and leak valves. A differentially pumped quadrupole mass spectrometer (Balzers) was connected through a leak valve to the experimental cell and the gas phase composition was monitored by on-line mass spectrometry, while simultaneously characterizing the surface by XPS. The $\mathrm{CO}$ to $\mathrm{CO}_{2}$ exit ratio was calculated by $m / e 28$ and 44 respectively, taking into account relative sensitivities measured in a reference experiment. A correction of m/e 28 signal due to $\mathrm{CH}_{3} \mathrm{OH}$ fragment (26\% of $\mathrm{m} / \mathrm{e}$ 31) was also considered.

Characterization of the as-received/fresh sample in UHV revealed significant quantities of carbonates and nitrate species. Therefore prior to the catalytic testing the sample was pre-treated in the XPS reaction cell by oxidation $\left(0.5 \mathrm{mbar}_{2}\right.$ at $\left.670 \mathrm{~K}\right)$ and reduction $\left(0.5 \mathrm{mbar}_{2}\right.$ at

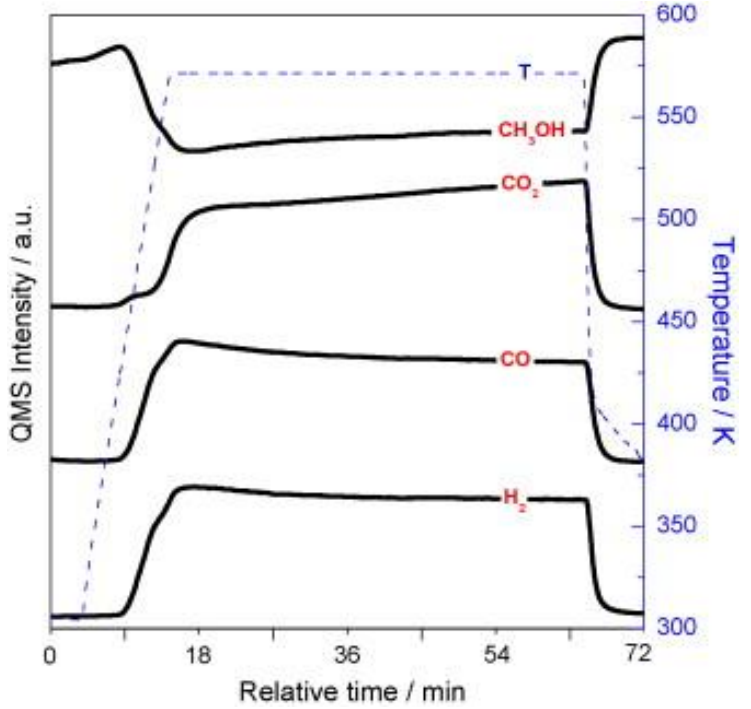

Fig. 1: Normalized on-line mass spectrometry data recorded upon heating the PtRuCo catalyst in a $\mathrm{CH}_{3} \mathrm{OH}: \mathrm{H}_{2} \mathrm{O}=1$ :2 reaction mixture in a total pressure of 0.5 mbar. The doted (blue) line is the sample temperature corresponding to the right $y$-axis.

$570 \mathrm{~K})$ cycles, until all carbon and nitrogen traces disappeared. Core-level photoelectron spectra were recorded at $570 \mathrm{~K}$ in an overall pressure of $0.5 \mathrm{mbar}$. For the $\mathrm{CH}_{3} \mathrm{OH}$ and $\mathrm{CO}$ reaction measurements the $\mathrm{CH}_{3} \mathrm{OH}: \mathrm{H}_{2} \mathrm{O}$ and $\mathrm{CO}: \mathrm{H}_{2} \mathrm{O}$ mixing ratios were $1: 2$ and $1: 10$ respectively. The $\mathrm{Pt} 4 \mathrm{f}, \mathrm{Ru} 3 \mathrm{~d}$, Co 2p, Co 3p, C 1s and O 1s spectra were recorded using appropriately selected excitation photon energies, resulting in photoelectrons with two characteristic kinetic energies for each spectrum, namely 180 and $580 \mathrm{eV}$. In that way information at two different analysis depths was collected $\left(\lambda_{[180 \mathrm{eV}]} / \lambda_{[580 \mathrm{eV}]}=0.56\right)[18]$. All spectra were normalized by the incident photon flux, which was measured prior to the measurements using a photodiode with known quantum efficiency. The spectra presented here are rescaled to facilitate the observation of peak characteristics. All binding energies (BE) given are calibrated with respect to the Fermi Edge of the analyzer. Background subtraction was carried out by Shirley method. Quantitative calculations were performed using normalized $\mathrm{Pt} 4 \mathrm{f}, \mathrm{Ru} 3 \mathrm{~d}$, Co $2 p$, Co $3 p, C$ s and $\mathrm{O} 1 \mathrm{~s}$ intensities, taking into account the photon-energy dependence of the atomic subshell photo-ionization cross-sections [19].

\section{Results and Discussion}

\subsection{On-line mass spectrometry results}

On-line mass spectrometry results for $\mathrm{CH}_{3} \mathrm{OH}$ oxidation in the presence of water are given in Fig. 1, together with the temperature profile (right hand axis). The activity of the catalyst is demonstrated by the detection of the reaction products $\mathrm{H}_{2}, \mathrm{CO}$ and $\mathrm{CO}_{2}(m / e=2,28$, and 44 respectively) in the gas phase and the consumption of $\mathrm{CH}_{3} \mathrm{OH}$ 

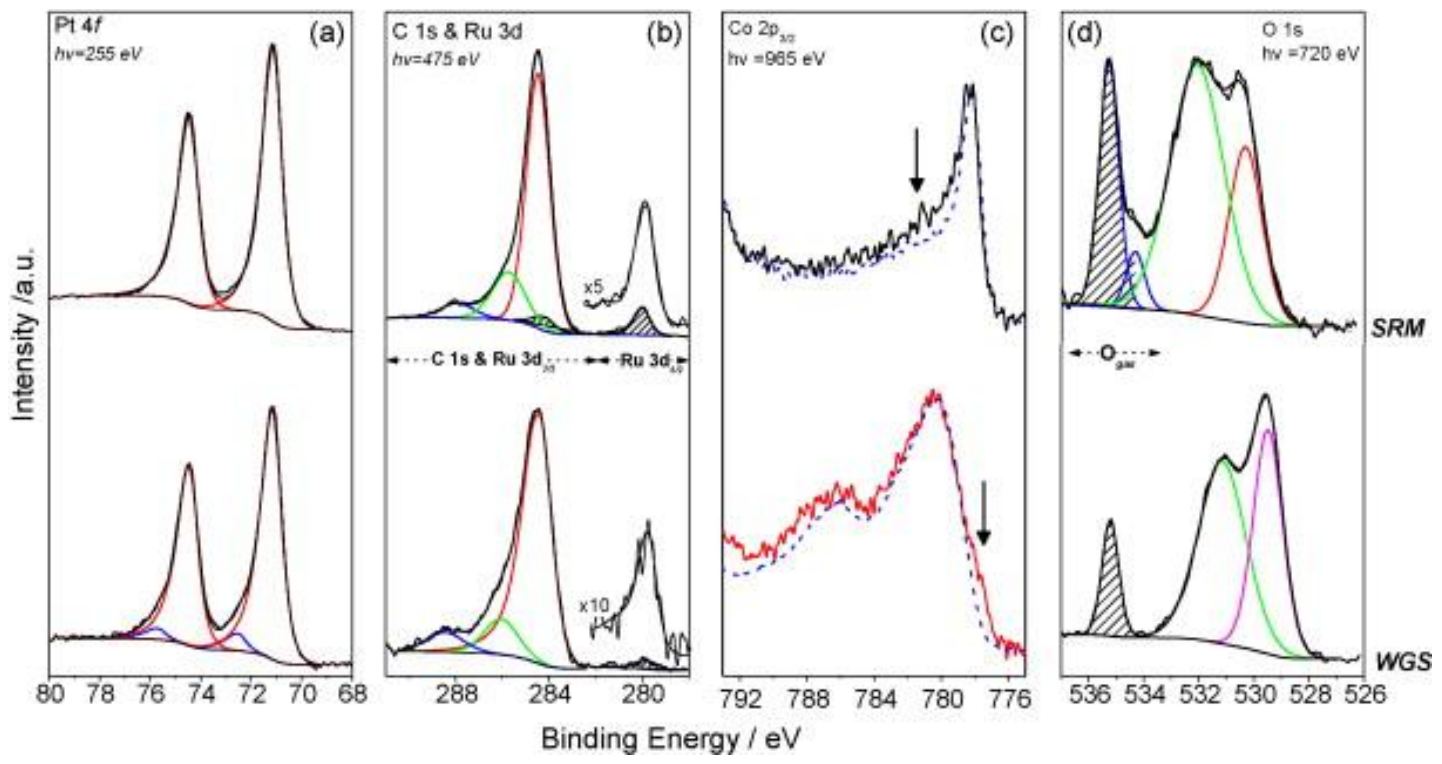

Fig. 2: Core-level photoelectron peaks of PtRuCo catalyst, recorded in $\mathrm{CH}_{3} \mathrm{OH}: \mathrm{H}_{2} \mathrm{O}=1: 2$ (SRM) and $\mathrm{CO}: \mathrm{H}_{2} \mathrm{O}=1: 10$ (WGS) reaction mixtures in a total pressure of $0.5 \mathrm{mbar}$, at $570 \mathrm{~K}$ : (a) Pt 4f, (b) C 1s and Ru 3d (in shaded peak), magnification of the Ru $3 \mathrm{~d}_{5 / 2}$ peak recorded using $h v=865 \mathrm{eV}$ is presented above, (c) Co 2 $\mathrm{p}_{3 / 2}$, dashed lines are reference curves of metallic Co (top) and CoO (bottom) recorded in the same set-up and (d) $\mathrm{O}$ 1s, gas phase peaks due to $\mathrm{CH}_{3} \mathrm{OH}$ and $\mathrm{H}_{2} \mathrm{O}$ appears above $534 \mathrm{eV}$ (in shaded peak).

$(m / e=31)$ upon rising the temperature from 310 to $570 \mathrm{~K}$. When the catalyst is cooled the reaction stops and the MS signal returns to the initial (before reaction) values. From this figure methanol conversion of about $35 \%$ and a $\mathrm{CO}: \mathrm{CO}_{2}$ ratio of $4: 1$ was calculated.

The production of $\mathrm{H}_{2}, \mathrm{CO}$ and $\mathrm{CO}_{2}$ from a $\mathrm{CH}_{3} \mathrm{OH}$ and $\mathrm{H}_{2} \mathrm{O}$ reaction mixture, may involve several reaction pathways frequently discussed in the literature. Among them methanol steam reforming reaction (SRM) [20] and [21]:

$\mathrm{CH}_{3} \mathrm{OH}+\mathrm{H}_{2} \mathrm{O} \rightarrow \mathrm{CO}_{2}+3 \mathrm{H}_{2}$

is usually performed with high selectivities on copper based catalysts, while on noble metals methanol decomposition is also observed [22]:

$\mathrm{CH}_{3} \mathrm{OH} \rightarrow \mathrm{CO}+2 \mathrm{H}_{2}$

In the presence of water, adsorbed $\mathrm{CO}\left(\mathrm{CO}_{\mathrm{ads}}\right)$ undergoes further oxidation through the water gas shift reaction (WGS):

$\mathrm{CO}_{\text {ads }}+\mathrm{H}_{2} \mathrm{O} \rightarrow \mathrm{CO}_{2}+\mathrm{H}_{2}$

which is reported to be the preferential reaction pathway on PtRu catalyst [11]. The CO: $\mathrm{CO}_{2}$ ratio of $4: 1$ found here points to a significant rate of methanol decomposition (reaction (2)), however reactions (1) and/or (3) should also taking place as indicated by the $\mathrm{CO}_{2}$ production.

The WGS reaction was studied separately by exposing the PtRuCo catalyst to a CO/ $\mathrm{H}_{2} \mathrm{O}$ mixture rich in $\mathrm{H}_{2} \mathrm{O}(1: 10)$ at $570 \mathrm{~K}$. This ratio is similar to the $\mathrm{CO} / \mathrm{H}_{2} \mathrm{O}$ ratio recorded during the SRM reaction. The CO consumption was very low (around 2\%), but the catalytic activity was also confirmed by $\mathrm{H}_{2}$ and $\mathrm{CO}_{2}$ production (data not shown). However it should be noted that the aim was not to measure the catalyst at optimum WGS reaction performance, but to compare the two reactions under similar conditions.

\subsection{In situ XPS results}

\subsubsection{Comparison of SRM and WGS reactions over PtRuCo catalyst}

Photoelectron spectroscopy results for both reactions were recorded under working catalytic conditions (total pressure 0.5 mbar, $570 \mathrm{~K}$ ). In Fig. 2, Pt 4f, C $1 \mathrm{~s}$, Ru $3 \mathrm{~d}_{5 / 2}$, Co $2 \mathrm{p}_{3 / 2}$ and $\mathrm{O} 1 \mathrm{~s}$ photoelectron peaks for SRM (top) and WGS (bottom) reactions over the PtRuCo catalyst, are presented. For SRM reaction Pt is in the zero-valence state as indicated by the narrow $\mathrm{Pt} 4 \mathrm{f}_{7 / 2}$ peak at $71.1 \mathrm{eV}$. Analysis of the $\mathrm{Ru} 3 \mathrm{~d}$ peak is obscured by the strong $\mathrm{C} 1 \mathrm{~s}$ signal due to the presence of adsorbed carbon species formed during reaction. However, the overlapping concerns mainly the $\mathrm{Ru}$ $3 \mathrm{~d}_{3 / 2}$ component while the $\mathrm{Ru} 3 \mathrm{~d}_{5 / 2}$ can be clearly distinguished, as shown in Fig. $2 b$ where the energy region for both $\mathrm{C} 1 \mathrm{~s}$ and $\mathrm{Ru} 3 \mathrm{~d}$ is shown. Hydrocarbon and/or graphitic carbon species located at $284.4 \mathrm{eV}$ dominate the $\mathrm{C} 1 \mathrm{~s}$ region [23] and [24]. Two additional components at 286.0 and $288.2 \pm 0.2 \mathrm{eV}$ are assigned to oxygen bound carbon species; alcohol/carbonyl groups and formate groups respectively [23], [24] and [25]. The $\mathrm{Ru} 3 \mathrm{~d}_{5 / 2}$ peak at $280.0 \mathrm{eV}$ is very close to the binding energy previously 
measured on clean metallic Ru ( $\left.\begin{array}{llll}0 & 0 & 0 & 1\end{array}\right)$ in the same set-up [26]. The Co $2 \mathrm{p}_{3 / 2}$ peak (solid black line) shown in Fig. 2c is centered at $778.2 \mathrm{eV}$ and is accompanied by weak satellite structure at higher energies. The BE and the weak satellite structure is characteristic of metallic cobalt $\left(\mathrm{Co}^{0}\right)$ [27] and [28]. However, comparison of Co $2 \mathrm{p}_{3 / 2}$ regions recorded under SRM with fully reduced Co recorded in pure $\mathrm{H}_{2}$ (dashed blue line), revealed some extra features around $781 \mathrm{eV}$ (indicated in the graph by an arrow). This is a sound indication of ionic cobalt species $\left(\mathrm{Co}^{x+}\right)$ mixed with the dominant $\mathrm{Co}^{0}$ phase [27], [28] and [29].

The $\mathrm{O} 1 \mathrm{~s}$ spectrum in Fig. $2 \mathrm{~d}$ shows a complex structure, indicative of a number of different oxygen species on the sample surface. In order to fit the $O 1$ s curve two oxygen components were used (plus two components for $\mathrm{CH}_{3} \mathrm{OH}$ and $\mathrm{H}_{2} \mathrm{O}$ gas phase above $534 \mathrm{eV}$, shown as patterned peaks) with quite broad peak widths, taking into account that each component probably contains various oxygen species close in BE [14]. Two components at 530.3 and $532 \mathrm{eV}$ with FWHM 1.4 and $2.2 \mathrm{eV}$ respectively, emerge from the fitting. Depth dependent measurements using higher photon energies (see also below) indicated that the peak at $530.3 \mathrm{eV}$ is to a large extent due to sub-surface species. However the position of this peak is shifted about $0.8 \mathrm{eV}$ as compared to that of the lattice oxygen peak of $\mathrm{CoO}$ and $\mathrm{Co}_{3} \mathrm{O}_{4}$ oxides (at $529.5 \pm 0.2 \mathrm{eV}$ ), reported in the literature [30] and measured on reference compounds in the same set-up [31]. The interpretation of $530.3 \mathrm{eV}$ peak will be given below in combination with other results. The broad, surface located, peak at $532 \mathrm{eV}$ most probably is a convolution of peaks due to various types of chemisorbed oxygen species, including $\mathrm{OH}$ groups [23], [32] and [33].

In the lower section of Fig. 2 photoelectron peaks recorded during the WGS reaction are shown. Apart from the main Pt 4f peak at 71.1 eV a new Pt doublet at $72.5 \mathrm{eV}$ is needed to fit the overall Pt $4 \mathrm{f}$ spectrum (Fig. 2a). The component at $72.5 \mathrm{eV}$ can be attributed to ionic platinum, most probably due to hydroxyl-Pt complexes [34]. It should be noted that the component at $72.5 \mathrm{eV}$, was much less pronounced when the $\mathrm{Pt} 4 \mathrm{f}$ peak was recorded using higher photon energies (not shown), indicating that the $72.5 \mathrm{eV}$ peak is primarily located at the surface. In the $\mathrm{C} 1 \mathrm{~s}$ region (Fig. 2b) the main component appears at $284.4 \mathrm{eV}$, while carbon-oxygen species are indicated by the components at 286.2 and $288.4 \mathrm{eV}$, very similar to those observed under SRM reaction conditions. The Ru $3 \mathrm{~d}$ peak is severely attenuated, and hardly resolved. In the magnified spectra, recorded using higher photon energy, the $\mathrm{Ru} 3 \mathrm{~d}_{5 / 2}$ peak at $280.0 \mathrm{eV}$ can be seen, pointing to metallic $\mathrm{Ru}$ as described above. Cobalt (Fig. 2c) is mainly in the oxide form under WGS reaction conditions, as indicated by the BE position of the main peak at $780.4 \mathrm{eV}$ and the intense satellite structure at the high BE side [29] and [30]. Comparison with reference a $\mathrm{CoO}$ spectrum reveals an extra bump to the low $\mathrm{BE}$ side of the peak (indicated by an arrow). The position of this extra feature at about $778 \mathrm{eV}$ indicates that a small portion of reduced/metallic cobalt coexists with cobalt oxide under WGS reaction conditions.
To deconvolute the $\mathrm{O}$ 1s spectrum in Fig. 2d, three components were used; two non-gas phase components at 529.4 and $531.2 \mathrm{eV}$ (FWHMs 1.3 and $2.0 \mathrm{eV}$ respectively) and one for gas phase $\mathrm{H}_{2} \mathrm{O}$ above $534 \mathrm{eV}$ (patterned peak). Due to the very low CO partial pressure $(0.04$ mbar) gas phase CO is not visible. Depth dependent measurements indicted that the $529.4 \mathrm{eV}$ component is located in deeper layers compared to that at $531.2 \mathrm{eV}$. In accordance, the BE at $529.4 \mathrm{eV}$ is indicative of lattice oxygen due to $\mathrm{CoO}$ and/or $\mathrm{Co}_{3} \mathrm{O}_{4}(529.5 \pm 0.2 \mathrm{eV}$ see also above $)$ [31], in full agreement with the cobalt oxide evidence in the Co $2 \mathrm{p}_{3 / 2}$ region. As described above the broad surface component at $531.2 \mathrm{eV}$ is a convolution of various oxygen species including defective cobalt sub-oxides $\left(\mathrm{CoO}_{x}\right)$, adsorbed $\mathrm{OH}$ groups, methoxy and formate species [14] and [24].

The C, O, Pt, Ru and Co atomic ratios, under SRM and WGS reaction conditions, were calculated assuming homogeneous distribution of the elements on the surface [18] and using theoretical cross-sections from reference [19]. It should be noted that this model is a required approximation, since the precise distribution of the catalyst components on the surface is practically unknown. Therefore only comparison of the calculated ratios and not absolute values will be considered here. In Fig. $3 a$ and $b$ the atomic ratios for SRM and WGS reactions respectively, at two information depths (1.8 and $3.2 \mathrm{~nm}$ ) [35], are given. It is evident that for both reactions $\mathrm{C}$ and $\mathrm{O}$ ratios (contains both the surface and the sub-surface oxygen components) are higher in the surface mode, while $\mathrm{Pt}, \mathrm{Ru}$ and Co show the opposite trend. This observation shows that carbon and an oxygen species are located to a large extent on the surface of PtRuCo catalyst. By dividing the oxygen contribution into surface adsorbed $\left(\mathrm{O}_{\mathrm{ads}}\right)$ and sub-surface $\left(\mathrm{O}_{\mathrm{sub}}\right)$ oxygen species following the deconvolution procedure shown in Fig. 2d, it is evident that the main oxygen contribution in the most surface sensitive mode $(1.8 \mathrm{~nm})$ is from $\mathrm{O}_{\text {ads }}$ species, confirming the assignment of the two oxygen components at different depths.

In Fig. 3c atomic ratios from SRM and WGS reactions are compared using spectra recorded at the same information depth $(3.2 \mathrm{~nm})$. Significantly higher carbon amounts were observed during SRM, while oxygen species (adsorbed and due to $\mathrm{CoO}_{x}$ ) dominates in WGS reaction. In addition, there is a major influence of the reaction mixture on the $\mathrm{Pt}$ and $\mathrm{Co}$ atomic ratio signifying substantial surface rearrangement. In particular, in the SRM reaction the surface is Pt enriched, while during WGS cobalt atomic ratio is enhanced (see Fig. 2c). This is a strong indication of Co segregation over Pt and Ru during WGS reaction. Surface segregation, i.e. the enrichment of one element at the surface relative to the bulk, is not unusual in bulk metal alloys [4] and [36]. Since segregation is kinetically limited, temperature is an important factor in this process. The above presented results are referred to isothermal and isobaric conditions; therefore surface composition transformations are primarily related to the redox properties of the gas mixtures. 

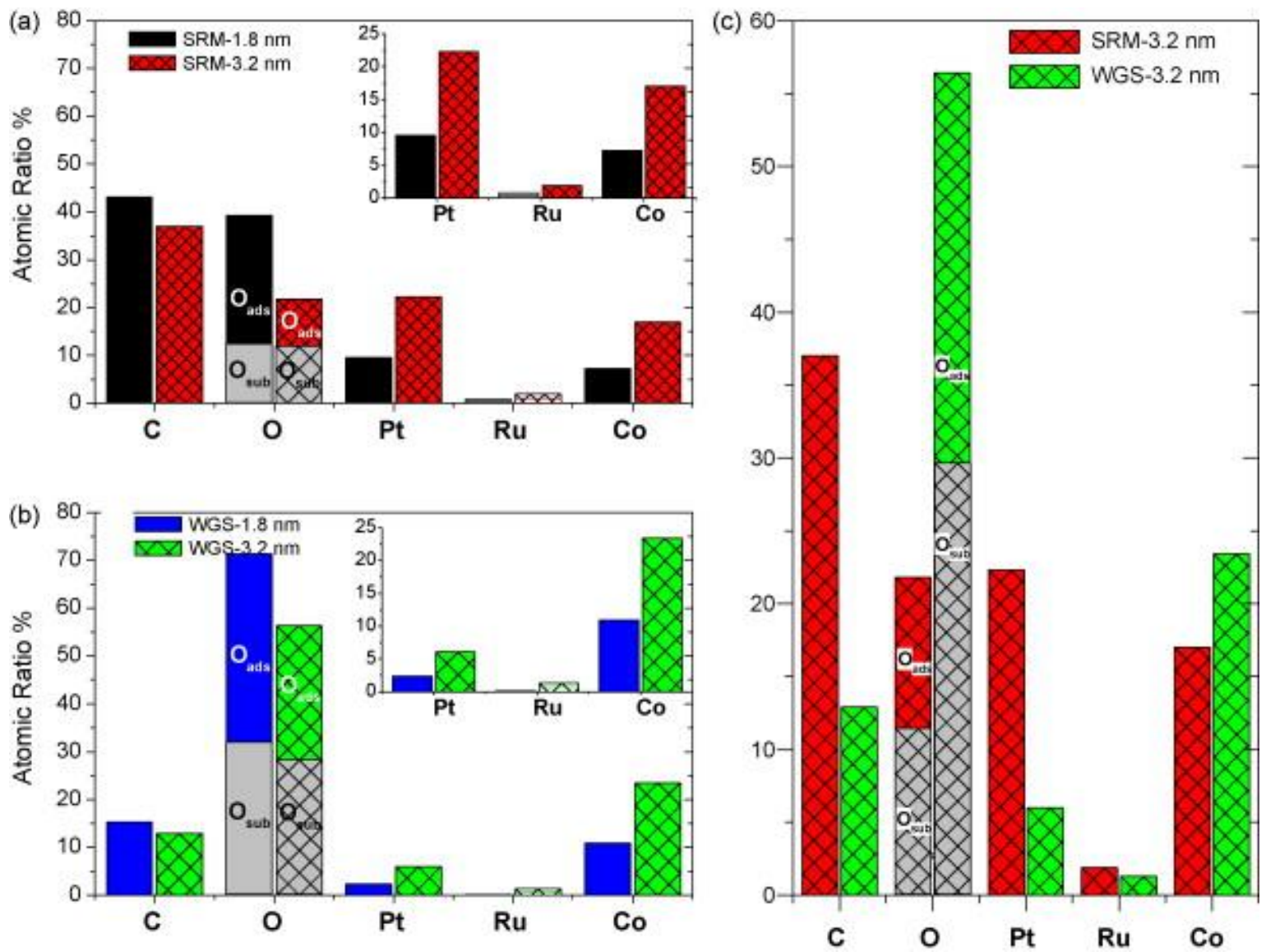

Fig. 3: Surface atomic ratio of C, O (both adsorbed and sub-surface species), Pt, Ru and Co calculated for (a) SRM reaction using photoelectron peaks recorded at two different kinetic energies, resulting in average information depths of 1.8 and $3.2 \mathrm{~nm}$. The inset shows the magnification of atomic ratios for $\mathrm{Pt}, \mathrm{Ru}$ and $\mathrm{Co}$, (b) as in (a) but for WGS reaction and (c) comparison of surface atomic ratio between SRM and WGS reaction using the results of $3.2 \mathrm{~nm}$ information depth. All data were recorded under working catalytic conditions ( $570 \mathrm{~K}$ and total pressure of $0.5 \mathrm{mbar}$ ).

\subsubsection{SRM reaction over polycrystalline PtCo foil}

From the above presented results it is evident that under WGS reaction conditions cobalt is oxidized and segregates on the surface, most probably encapsulating platinum. However, apart from the significant carbon deposition, little can be said about the PtRuCo surface composition during SRM reaction. The structural complexity and the inhomogeneity of the PtRuCo powder obscure a precise description of the surface and impose to study of a better defined model system. Therefore, the SRM reaction was studied over a polycrystalline PtCo (1:1)-alloyed foil, under identical pretreatment, temperature and gas mixture composition to the PtRuCo catalyst (only the overall pressure was kept slightly lower at $0.3 \mathrm{mbar}$, in order to enhance photoelectron signal). The gas phase analysis indicated that PtCo is also active for the SRM reaction, although much lower methanol conversion rate (around $10 \%$ ) was observed compared to PtRuCo catalyst (35\%), apparently due to the lower surface area of the foil compared to the powder.
The spectroscopic results under reaction conditions were pretty much identical to those found for PtRuCo catalyst. In particular, $\mathrm{Pt}$ is in the metallic state, extra features at about $781 \mathrm{eV}$ observed in the Co $2 \mathrm{p}_{3 / 2}$ spectrum and significant amounts of carbon were deposited on the surface (Pt 4 f and C 1 s peaks are not shown here). The $\mathrm{O} 1 \mathrm{~s}$ peaks obtained under SRM conditions at two photoelectron kinetic energies (information depths) are presented in Fig. 4. Apart from the gas phase contribution which is visible above $534 \mathrm{eV}$ (shaded peak), two additional oxygen species at $530.3(1.7 \mathrm{eV})$ and $532.4(2.0 \mathrm{eV}) \mathrm{eV}$ are clearly distinguishable (in parenthesis the FWHM of the peak is given). The relative intensity of the low $\mathrm{BE}$ component at $530.3 \mathrm{eV}$ is increasing as the information depth increases, indicating that this component is mainly from sub-surface oxygen species. In agreement with the results found on PtRuCo, the binding energy of the sub-surface component at $530.3 \mathrm{eV}$ does not correspond to any known cobalt oxide phase. The surface component at $532.4 \mathrm{eV}$ is assigned to various types of adsorbed oxygen species as described above (see comments of Fig. 2d). 


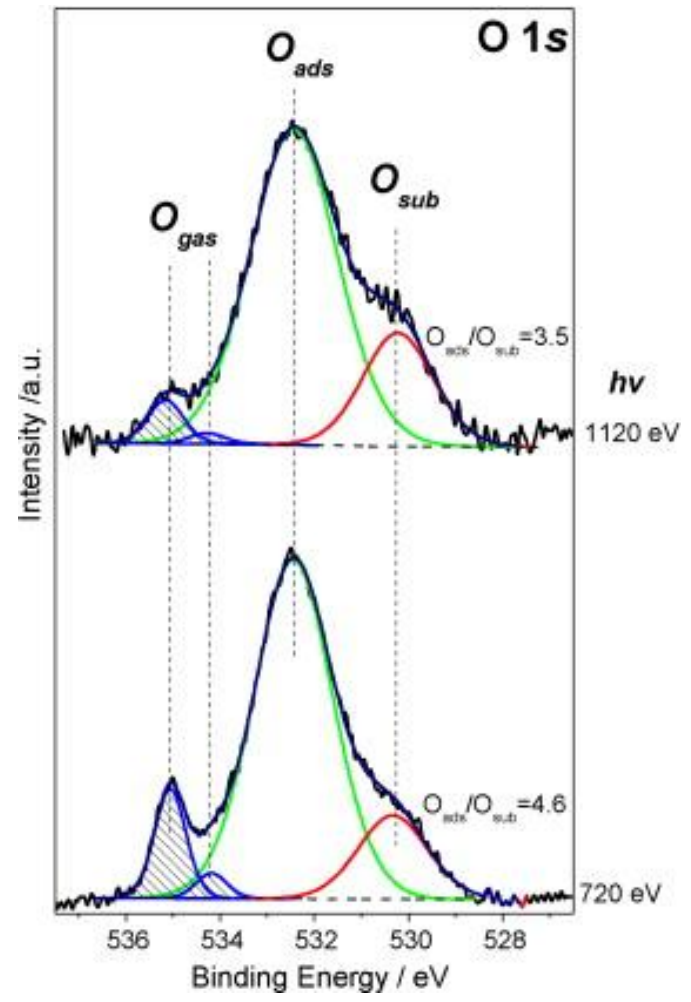

Fig. 4: The O 1s peak obtained on a polycrystalline PtCo foil under SRM reaction conditions (at $570 \mathrm{~K}$, total pressure $0.3 \mathrm{mbar}$ ) using two different excitation energies $(h v)$, resulting in two electron kinetic energies (KE) and information depths (ID): (i) $h v=720 \mathrm{eV}, \mathrm{KE}=190 \mathrm{eV}, \mathrm{ID} \sim 1.8 \mathrm{~nm}$ and (ii) $h v=1120 \mathrm{eV}$, $\mathrm{KE}=590 \mathrm{eV}, \mathrm{ID} \sim 3.2 \mathrm{~nm}$. The gas phase components are shown in shaded peaks.

The depth distribution of Pt and Co over the first few atomic layers was investigated by non-destructive depth profile measurements. In brief, upon photo-ionization the photoelectron kinetic energy (KE), and thus the information depth [18], is determined by the core-level binding energy (BE) and the incident photon energy $(h v)[\mathrm{KE}=h v-\mathrm{BE}]$. To calculate each $\mathrm{Pt} 4 \mathrm{f} / \mathrm{Co} 2 \mathrm{p}$ atomic ratio, the incident energies for $\mathrm{Pt} 4 \mathrm{f}$ and Co $2 \mathrm{p}$ peaks were chosen such that the photoelectrons of both peaks originate within the same sample depth, i.e. the kinetic energies of $\mathrm{Pt} 4 \mathrm{f}$ and Co $2 \mathrm{p}$ photoelectrons are equal. Five different information depths are used for analysis. Evidently, the contribution of surface components is less influential as the electron kinetic energy increases. The $\mathrm{Pt} 4 \mathrm{f} / \mathrm{Co} 2 \mathrm{p}$ atomic ratio (normalized to the photon flux and the photo-ionization cross-section) is shown in Fig. 5. As the electron kinetic energy increases (deeper layers are probed) the Pt/Co intensity ratio generally increases. The only exception is the measurement at $180 \mathrm{eV}(\sim 1.7 \mathrm{~nm})$ for which a significantly lower Pt/Co ratio was measured. It should be noted that qualitatively similar results were found also under pure $\mathrm{H}_{2}$ atmosphere (data not shown), while reference experiment on PtCo layer prepared by atomic vapor deposition and measured at room temperature in vacuum, indicates a monotonic increase of Pt/Co (Fig. 5, open circles).

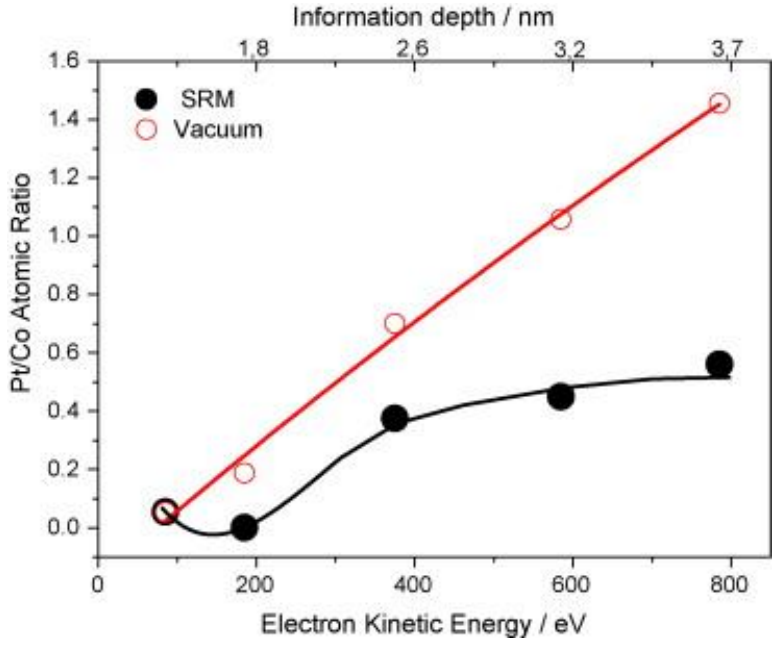

Fig.5: The Pt/Co atomic ratio calculated from the Pt $4 \mathrm{f}$ and Co $2 \mathrm{p}$ photoelectron peaks, as a function of the electron kinetic energy. Closed circles represent data recorded under SRM reaction conditions $(570 \mathrm{~K}$, total pressure $0.3 \mathrm{mbar}$ ) over PtCo polycrystalline foil. Open circles are measured in vacuum over a reference $2.5 \mathrm{~nm}$ PtCo layer deposited on $\mathrm{TiO}_{2}$ at room temperature. On the upper $x$ axis the estimated average information depth is given.

Increase of $\mathrm{Pt} / \mathrm{Co}$ ratio with the electron kinetic energy can be rationalized by two possible surface arrangement models. In the first (layer model) Pt and Co form a homogeneous mixture (alloy), with Pt preferentially located in the sub-surface region, while cobalt is mainly on the surface. Within the layer model, the decrease of $\mathrm{Pt} / \mathrm{Co}$ ratio at $\mathrm{EK}=180 \mathrm{eV}(\sim 1.7 \mathrm{~nm})$ could be explained by the formation of the so-called "Pt skin" layer proposed earlier to explain improved electrocatalytic performance of PtCo alloys [37]. Adsorbed carbon and oxygen species should form a homogeneous surface layer over the Pt skin.

A second more complex surface arrangement, which could explain the depth profile measurements, is a patched PtCo surface constituting of discrete $\mathrm{Pt}$ and Co areas (islands model). If carbon is preferentially deposited on Pt and not on Co, in the surface sensitive mode only the Pt photoelectron peak would be severely attenuated, and therefore the $\mathrm{Pt} / \mathrm{Co}$ ratio would be small. At higher electron KEs, Pt from deeper layers contributes to the $\mathrm{Pt} 4 \mathrm{f}$ signal, thus the $\mathrm{Pt} / \mathrm{Co}$ ratio increases. The island model, however, seems more unlikely since it cannot explain the drop in $\mathrm{Pt} / \mathrm{Co}$ ratio at $\mathrm{EK}=180 \mathrm{eV}$. In addition, ethanol reforming experiments on monometallic cobalt surfaces, under similar reaction conditions (data are not presented here), showed a significant amount of carbon deposited on cobalt surfaces. Therefore carbon deposition only on Pt arrays, which is a prerequirement for the island model, is not supported.

As mentioned above, extra features at about $781 \mathrm{eV}$ were observed at Co $2 \mathrm{p}_{3 / 2}$ peak during SRM reaction on PtCo, which could be assigned to traces of ionic cobalt species $\left(\mathrm{Co}^{x+}\right)$, in line with the observations on the PtRuCo catalyst (see Fig. 2c). The intensity ratio between the ionic $\left(\mathrm{Co}^{x+}\right)$ and metallic $\left(\mathrm{Co}^{0}\right)$ components in the $\mathrm{Co} 2 \mathrm{p}_{3 / 2}$ peak 


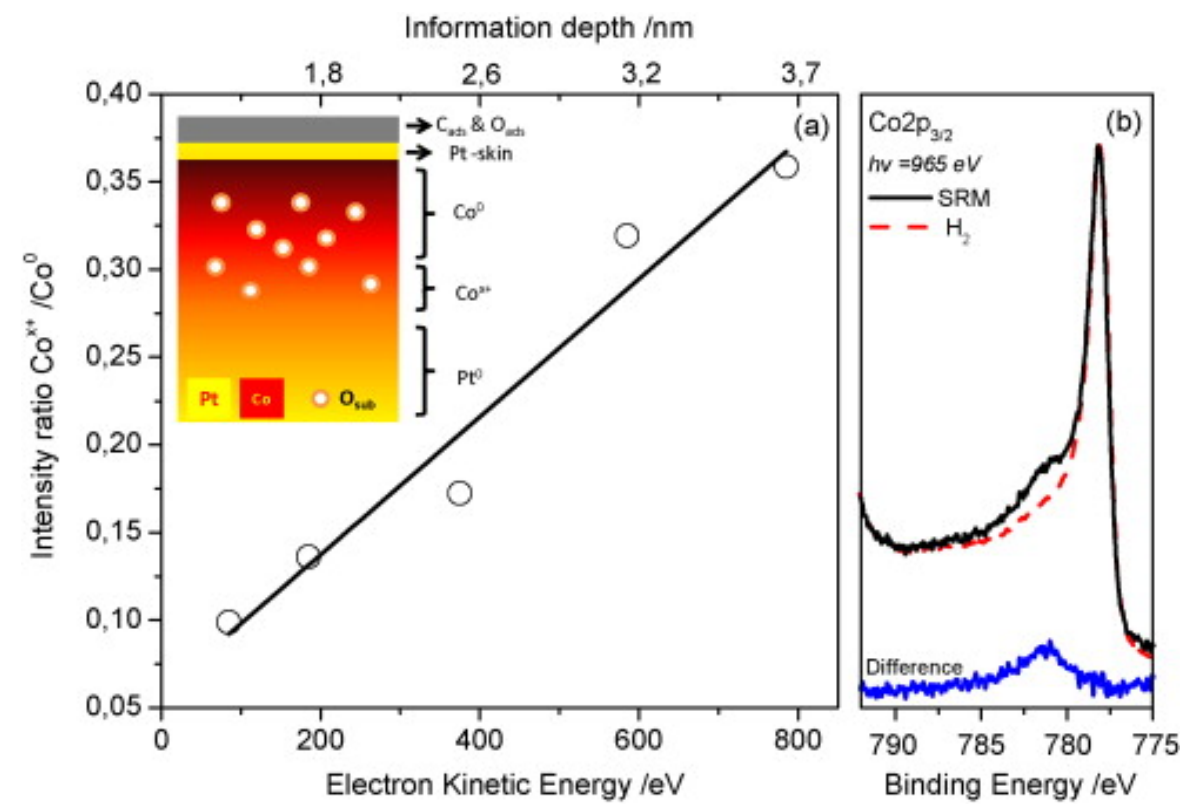

Fig. 6: (a) The ionic $\left(\mathrm{Co}^{x+}\right)$ to metallic $\left(\mathrm{Co}^{0}\right)$ cobalt intensity ratio as a function of the electron kinetic energy, measured over polycrystalline PtCo foil under SRM reaction conditions $(570 \mathrm{~K}$, total pressure $0.3 \mathrm{mbar})$. On the upper $x$-axis the estimated information depth is given. In the inset figure is a schematic representation of the proposed surface arrangement model of the PtCo foil, based on the depth profile results of [Fig. 4], [Fig. 5] and [Fig. 6] (note that the thickness of each layer is not in scale) and (b) characteristic example of Co $2 \mathrm{p}_{3 / 2}$ spectra subtraction.

for five different information depths is presented in Fig. 6a. The contribution of $\mathrm{Co}^{x+}$ species to the overall Co $2 \mathrm{p}_{3 / 2}$ spectrum (Fig. 6b) was obtained by subtraction of Co $2 p_{3 / 2}$ peaks recorded in SRM (full line) and in pure $\mathrm{H}_{2}$ (dashed line), using spectra excited with the same photon energy. The position of the difference peak at $781.2 \mathrm{eV}$, is shifted to higher $\mathrm{BEs}$ compared to $\mathrm{CoO} / \mathrm{Co}_{3} \mathrm{O}_{4}$ oxides measured in the same set-up, but is very close to literature reported values for $\mathrm{Co}(\mathrm{OH})_{2}$ (at around $780.9 \mathrm{eV}$ ) [29]. As shown in Fig. 6, the relative intensity of $\mathrm{Co}^{x+}$ increases as the electron KE/information depth increases, indicating that ionic cobalt species are mainly in the sub-surface region. By combining depth dependent information presented in [Fig. 4], [Fig. 5] and [Fig. 6], a schematic model is proposed (see inset of Fig. 6a), to describe the average arrangement of the first few atomic layers (up to $4 \mathrm{~nm}$ ) of the PtCo surface under SRM reaction conditions. The driving force for surface segregation observed in the reaction mixture is the oxygen chemical potential, as proposed by theoretical investigations of diluted PtRu surfaces [38]. In addition similar arguments were recently proposed to explain surface restructuring of $\mathrm{Rh}-\mathrm{Pd}$ nanoparticles observed under oxidizing and reducing conditions [39].

\subsection{General discussion}

Overall, our study gave a rather detailed picture of the PtRuCo surface composition and valence state in two reaction environments. It is thus interesting to comment on the origin of the enhanced catalytic activity of bimetallic and ternary Pt-based catalysts. Two main models have been put forward in the literature; the "bifunctional effect", in which admixtures like Co and Ru supply adsorbed oxygen species to oxidize carbonaceous adsorbents on Pt sites, and the "ligand" or "electronic effect", in which the electronic properties of $\mathrm{Pt}$ are affected by the presence of admixture metals, so as its adsorption properties [5] and [11]. In both models the presence of $\mathrm{Pt}$ on the surface is essential for the catalytic activity. This fact is also supported here by the low CO consumption observed for WGS reaction, where spillover of cobalt oxide over Pt was observed. It is interesting to note that the abundance of adsorbed oxygen species at around 531.2 eV during WGS reaction ([Fig. 2] and [Fig. 3]), does not seem to favor the $\mathrm{CO}$ oxidation rate, qualifying these species mainly as non-reactive. In SRM reaction, the evidence of Pt-rich surface nicely correlates with the high methanol conversion rates. However, no evidences were found that the electronic structure of $\mathrm{Pt}$ is influenced by the presence of $\mathrm{Co}$ and $\mathrm{Ru}$ additives or by the reaction mixture. On the other hand, a complex sub-surface arrangement including oxygen and cobalt ions (not cobalt oxide), was revealed.

Our experimental evidences could not indicate a single type of active sites, and thus a sole promoting mechanism, involved in both reactions. What is even more unlikely is that the same active sites could survive in different reaction environments, taking into account the drastic modifications observed here upon switching the reaction mixture. A balance between "bifunctional" and "ligand" active sites, depending on the reaction environment, appears more plausible. However, one should also not overlook the role 
that sub-surface species, like oxygen, could play in such promoting schemes. An alternative mechanism could describe the role of $\mathrm{Ru}$ and Co promoters as reservoirs for sub-surface oxygen. Such sub-surface species may act in two ways: either by emerging on the surface and directly participate to the reaction or by modifying the Pt local electronic structure by inducing strain in platinum crystal lattice, as was recently proposed for the SRM reaction on $\mathrm{ZnO}$ supported $\mathrm{Cu}$ catalysts [14].

\section{Summary and conclusions}

The surface of an unsupported PtRuCo catalyst under SRM $\left(\mathrm{CH}_{3} \mathrm{OH}: \mathrm{H}_{2} \mathrm{O}\right)$ and WGS $\left(\mathrm{CO}: \mathrm{H}_{2} \mathrm{O}\right)$ reaction conditions $(P=0.5 \mathrm{mbar}, T=570 \mathrm{~K})$, was characterized by ambient pressure photoelectron spectroscopy. Gas phase analysis of the products indicated that in the SRM reaction the catalyst is relatively active, but not hydrogen selective, while during WGS at the same $P, T$ conditions the activity was much lower. It was clearly demonstrated that the surface of PtRuCo catalyst is dynamic and undergoes significant modifications in its composition and chemical state, in response to the reaction mixture. In particular, under SRM reaction conditions $\mathrm{Pt}$ and $\mathrm{Ru}$ were metallic, while apart from the dominant $\mathrm{Co}^{0}$ state, traces of ionic $\mathrm{Co}^{x+}$, were also observed. Significant amounts of adsorbed carbon and oxygen species were attached to the surface under working conditions, while indications of sub-surface (not lattice) oxygen were also found.

Rich in water WGS mixture favors surface oxidation of the PtRuCo reflecting the higher oxygen chemical potential compared to the SRM mixture. The surface of PtRuCo catalyst responded fast to the reaction environment by significant surface reconstruction. In particular during WGS cobalt segregates over platinum and is, to a large extent, oxidized. Interestingly, traces of ionic Pt species were also observed, while Ru was mainly metallic. Adsorbed carbon

\section{References}

[1] A. Hammnett, Catal. Today 38 (1997), p. 445

[2] G.T. Burstein, J. Barnett, A.R. Kucernak and K.R. Williams, Catal. Today 38 (1997), p. 425.

[3] C. Lamy, J.M. Leger, J. Clavilier and R.J. Parsons, Electroanal. Chem. 150 (1983), p. 71.

[4] N.M. Markovic and P.N. Ross, Surf. Sci. Rep. 45 (2002), p. 117.

[5] R. Liu, H. Iddir, Q. Fan, G. Hou, A. Bo, K.L. Ley, E.S. Smotkin, Y.-E. Sung, H. Kim, S. Thomas and A. Wieckowski, J. Phys. Chem. B 104 (2000), p. 3518.

[6] M. Watanabe, M. Vehida and S. Motoo, J. Electroanal. Chem. 229 (1987), p. 395

[7] P. Waszczuk, G.Q. Lu, A. Wieckowski, C. Lu, C. Rice and R.I. Masel, Electrochim. Acta 47 (2002), p. 3637.

[8] G. Samjeske, H. Wang, T. Loffter and H. Baltruschat, Electrochim. Acta 47 (2002), p. 3681.

[9] M. Gotz and H. Wendt, Electrochim. Acta 43 (1998), p. 3637. and oxygen species were formed, though compared to SRM reaction relatively less carbon and more oxygen was found.

The photoelectron spectroscopy results represent an average surface state and the ternary PtRuCo catalyst is too complex to give unambiguous structure-catalytic activity relationship. In order to get a more detailed description of the system and confirm the trends found on PtRuCo, the SRM reaction was studied over polycrystalline PtCo foil. The results showed that the outermost layers are enriched with cobalt, though depth profile measurements gave indications of a Pt-rich or a "Pt-skin" layer over the outermost cobalt layers. The presence of sub-surface oxygen and ionic cobalt species was confirmed. The ionic cobalt species are to a large extent diluted in the sub-surface region.

The detailed characterization of PtRuCo surface structure may provide the basis for understanding the role of $\mathrm{Ru}$ and Co promoters, in multi-component Pt catalysts. The chemical nature of the promoters should strongly influence their promoting effect. Our study clearly demonstrates that the reaction mixture can induce drastic changes on the surface composition and the chemical state of the catalyst. As was recently proposed [14], such promoters may store oxygen species which in a reducing reaction cycle can segregate on the surface and participate (directly or act as structure stabilizers) in the reaction. However the description of the reaction mechanism requires further experiments which are under way.

\section{Acknowledgements}

The authors would like to thank the BESSY staff for help in carrying out the experiments. G.P. F.P and S.G.N. gratefully acknowledge the EU (Grant number: RII 3 CT2004-506008) and S.Z. the BESSY II EUSA programme for financial support during the experiments.

[10] P. Shen, K. Chen and A.C.C. Tseung, J. Electrochem. Soc 142 (1995), p. L85.

[11] J.S. Spendelow, P.K. Babu and A. Wieckowski, Curr. Opin. Solid State Mater. Sci. 9 (2005), p. 37.

[12] P. Strasser, Q. Fan, M. Devenny, W.H. Weinberg, P. Liu and J.K. Norskov, J. Phys. Chem. B 107 (2003), p. 11013.

[13] T. Huang, X. Wang, J. Zhuang, W.-B. Cai and A. Yu, Electrochem. Solid-State Lett. 12 (2009), pp. B112-B115.

[14] M. Salmeron and R. Schlögl, Surf. Sci. Rep. 63 (2008), p. 169.

[15] B. Moreno, J.R. Jurado and E. Chinarro, Catal. Commun. 11 (2009), p. 123

[16] H. Bluhm, M. Hävecker, A. Knop-Gericke, E. Kleimenov, R. Schlögl, D. Teschner, V.I. Bukhtiyarov, D.F. Ogletree and M. Salmeron, J. Phys. Chem. B 108 (2004), p. 14340.

[17] A. Knop-Gericke, E. Kleimenov, M. Hävecker, R. Blume, D. Teschner, S. Zafeiratos, R. Schlögl, V.I. Bukhtiyarov, V.V. Kaichev, I.P. Prosvirin, A.I. Nizovskii, H. Bluhm, A. Bari- 
nov, P. Dudin and M. Kiskinova, Advances in Catalysis vol. 52, Academic Press (2009) pp. 213.

[18] M.P. Seah (2nd ed.) In: D. Briggs and M.P. Seah, Editors, Practical surface Analysis vol. 1, Willey \& Sons, Chichester, UK (1990).

[19] J.J. Yeh and I. Lindau, Atom. Data Nucl. Data Tables 32 (1985), p. 1.

[20] A.W. Grant, J.H. Larsen, C.A. Perez, S. Lehto, M. Schmal and C.T. Campbell, J. Phys. Chem. B 105 (2001), p. 9273.

[21] G. Jacobs, P.M. Patterson, U.M. Graham, A.C. Crawford, A. Dozier and B.H. Davis, J. Catal. 235 (2005), p. 79.

[22] N. Iwasa and N. Takezawa, Top. Catal. 22 (2003), p. 215.

[23] N.M. Rodriguez, P.E. Anderson, A. Wootsch, U. Wild, R. Schlögl and Z. Paal, J. Catal. 197 (2001), p. 365.

[24] J. Torres, C.C. Perry, S.J. Bransfield and D.H. Fairbrother, J. Phys. Chem. B 106 (2002), p. 6265.

[25] J.G. Wang, W.X. Li, M. Borg, J. Gustafson, A. Mikkelsen, T.M. Pedersen, E. Lundgren, J. Weissenrieder, J. Klikovits, M. Schmid, B. Hammer and J.N. Andersen, Phys. Rev. Lett. 95 (2005), p. 256102.

[26] R. Blume, M. Hävecker, S. Zafeiratos, D. Teschner, E. Kleimenov, A. Knop-Gericke, R. Schlögl, A. Barinov, P. Dudin and M. Kiskinova, J. Catal. 239 (2006), p. 354

[27] J.W. Chai, J.S. Pan, S.J. Wang, C.H.A. Huan, G.S. Lau, Y.B. Zheng and S. Xu, Surf. Sci. 589 (2005), p. 32.

[28] C.R. Cho, J.P. Kim, J.Y. Hwang, S.Y. Jeong, Y.G. Joh and D.H. Kim, Jpn. J. Appl. Phys. 43 (2004), p. L1323.
[29] A.M. Saib, A. Borgna, J. van Loosdrecht, P.J. van Berge and J.W. Niemantsverdriet, J. Phys. Chem. B 110 (2006), p. 8657.

[30] M.A. Langell, J.G. Kim, D.L. Pugmire and W. McCarroll, J. Vac. Sci. Technol. A19 (2001), p. 1977.

[31] S. Zafeiratos, T. Dintzer, D. Teschner, R. Blume, M. Hävecker, A. Knop-Gericke and R. Schlögl, J. Catal. 269 (2010), p. 309.

[32] R. Denecke, Appl. Phys. A 80 (2005), p. 977.

[33] L.A. Langley, D.E. Villanueva and D.H. Fairbrother, Chem. Mater. 18 (2006), p. 169.

[34] J.E. Drawdy, G.B. Hoflund, S.D. Gardner, E. Yngvadottir and D.R. Schryer, Surf. Interface Anal. 16 (1990), p. 369.

[35] The information depth is estimated after multiplying the inelastic mean free path $(\lambda)$ by 3 .

[36] S. Piccinin, S. Zafeiratos, C. Stampfl, T.W. Hansen, M. Haevecker, D. Teschner, V.I. Bukhtiyarov, F. Girgsdies, A. Knop-Gericke, R. Schloegl and M. Scheffler, Phys. Rev. Lett. 104 (2010), p. 35503.

[37] H.T. Duong, M.A. Rigsby, W.-P. Zhou and A. Wieckowski, J. Phys. Chem. C 111 (2007), p. 13460.

[38] B.C. Han, A. Van der Ven, G. Ceder and B.-J. Hwang, Phys. Rev. B72 (2005), p. 205409.

[39] F. Tao, M.E. Grass, Y. Zhang, D.R. Butcher, J.R. Renzas, Z. Liu, J.Y. Chung, B.S. Mun, M. Salmeron and G.A. Somorjai, Science 322 (2008), p. 932 